\title{
La devastación de la tierra como expulsión de Mnemosyne
}

\author{
The Devastation of the Land \\ as Expulsion of Mnemosyne \\ Luis Fernando CARDOna SuÁREZ \\ Pontificia Universidad Javeriana Bogotá (Colombia) \\ fcardona@javeriana.edu.co
}

Recibido: 18/01/2015

Aceptado: 24/06/2015

\section{Resumen}

En el presente texto se quiere examinar la pertinencia de la caracterización heideggeriana de la devastación de la tierra como clave hermenéutica para asumir el decurso histórico de nuestro presente marcado por la guerra, la desolación y el exterminio sistemático de todo lo vivo. Siguiendo las indicaciones de Heidegger sobre la devastación provocada por la guerra, nos proponemos examinar su incremento como el destierro de Mnemosyne que no sólo hiela el alma, sino que ante todo desarma los espíritus para plantarle cara a su dolor. Y con ello queremos establecer un diálogo entre Heidegger y Hans Blumenberg en torno al fin de los tiempos, pues para ambos filósofos la devastación del mundo de la vida implica necesariamente el retorno de lo olvidado.

Palabras clave: Heidegger, Blumenberg, apocalipsis, destrucción, desierto, guerra, nihilismo, fin de los tiempos, salvación.

\begin{abstract}
The aim of this paper is to examine the relevance of Heidegger's characterization of the devastation of the earth as a hermeneutical key in order to understand the course of our present historical marked by war, desolation and the systematic extermination of all life. Following Heidegger's indications of the devastation caused by the war, we propose to examine its increase as the banishment of Mnemosyne that not only freezes the soul, but above all disarms the spirits to stand up to their pain. Thus we want to establish a dialogue between Heidegger and Hans Blumenberg around end of time, for both philosophers the devastation of the world of life necessarily involves the return of the forgotten.
\end{abstract}


Keywords: Heidegger, Blumenberg, apocalypse, destruction, desert, war, nihilism, end times, salvation.

\begin{abstract}
"Cuando oigáis estruendo de batallas y noticias de guerra, no se alarmen; eso tiene que suceder, pero no es todavía el final. Porque se alzará pueblo contra pueblo y reino contra reino, habrá terremotos en diversos lugares, habrá hambre; esos son los primeros dolores" (Mc. 13, 7-8) ${ }^{1}$.
\end{abstract}

A continuación, queremos sugerir algunos elementos para una fenomenología de la devastación con alcance metaforológico iluminados en estas palabras de Jesús, cuando predice la destrucción del templo y el fin del mundo ${ }^{2}$. Sin duda, estas palabras hablan de la crudeza del fin y del sufrimiento que se avecina y señalan la desolación que debe vivir el mundo humano para que se pueda finalmente escuchar la revelación de su sentido. Hoy podemos decir que hemos experimentado con creces esta desolación después de la guerra y la violencia generalizada que aún continua. Por esta razón, pensar nuestra condición histórica implica plantarle cara a estos primeros dolores que revelan el sentido del final. En las consideraciones de Heidegger sobre el fin de la guerra podemos, por ejemplo, encontrar algunos elementos que nos permiten asumir lo que aquí se nos ha abierto marcando el rumbo histórico del siglo Xx y comienzos del xxI. En el presente trabajo indicaremos estos elementos señalando, no obstante, que su comprensión debe ser asumida en un sentido metaforológico, pues la devastación que aquí se muestra hunde sus raíces en una eliminación más esencial, a saber, la expulsión de la dimensión de lo salutífero en el conjunto de la historia humana.

\title{
1. La guerra como figura histórica de la devastación
}

Cincuenta años después de la capitulación alemana de mayo de 1945 se publicó el pensamiento de Heidegger de finales de la guerra ${ }^{3}$. Se trata de una serie de diá-

\footnotetext{
${ }^{1}$ Las referencias de la Biblia se citaran de acuerdo con las abreviaturas acostumbradas y se seguirá la traducción de Alonso Schökel y Juan Mateos de los Institutos Bíblico y Oriental de Roma, publicados por las editoriales Ediciones Cristiandad y Editorial Verbo Divino, Madrid y Navarra, 1982.

${ }^{2}$ Para este análisis se seguirán los siguientes textos bíblicos: Mt. 24, 1-28. Lc. 21, 5-6; 7, 19.

${ }^{3}$ Nos referimos aquí a la publicación del tomo 77 de su obra completa bajo la dirección académica de Ingrid Schüßler. En este tomo se recogen tres conversaciones escritas entre los años 1944 y 1945. Este volumen apareció publicado en 1995 con el nombre de Feldweg-Gespräche. Tomando distancia del trabajo de Emmanuel Faye (Heidegger, l'introduction du nazisme dans la philosophie: Autour des séminaires inédits de 1933-1935, París, Le libre de Pouche, 2007; Heidegger: la introducción del nazismo en la filosofia en torno a los seminarios inéditos de 1933-1935, Madrid, Ediciones Akal, 2009), donde se busca demostrar cómo en los seminarios dictados por Heidegger al comienzo de la década de los treinta se pretende introducir tesis nacionalsocialistas al interior de la filosofía, para justificar con un sesgo claramente ideológico el decurso de los acontecimientos históricos que terminaron en el
} 
logos en los cuales el filósofo aborda aquí la problemática general de la destrucción de Alemania y de Europa, buscando alcanzar un punto de distancia que permita hacerle frente a lo que en la historia se nos muestra. Esta destrucción pone en escena el olvido del ser que se manifiesta ahora con toda su crudeza en el dominio de la técnica, dado que despliega el decurso histórico de la devastación de la tierra como anticipación del fin del mundo ${ }^{4}$.

genocidio judío, el profesor William Altman señala en su reciente trabajo publicado en el 2012 que la actitud de Heidegger frente a los acontecimientos de la guerra se debe, más bien, remontar a las década de los veinte, en particular a su encuentro polémico de 1929 con Ernst Cassirer en Davos. Es más, para Altman, el proyecto filosófico de Ser y tiempo debe ser comprendido como el esfuerzo teórico de su autor por asumir la devastación de Alemania generada en la Primera Guerra Mundial; esto explicaría por qué se privilegia en esta obra el ser-volcado-hacia-la-muerte como constitución originaria del estaren-el-mundo del Dasein frente a otras posibilidades igualmente existentivas abiertas en su finitud. Ser y tiempo sería entonces una invitación para que el pueblo alemán asumiera en la resolución de su misión histórica su destino más propio, encarar la crudeza de la muerte; esta situación cubre a Ser y tiempo con el aroma de una oración fúnebre (Grabrede) al estilo de Tucídides o de Ovidio (W. Altman, Martin Heidegger and the First World War. Being and Time as Funeral Oration, Maryland, Lexington Books, 2012, p. 216).

${ }^{4}$ Como sabemos, el problema del pensamiento apocalíptico en Heidegger ha sido objeto de una gran debate tanto por parte de sus seguidores como por sus más duros críticos (J. Derrida, Sobre un tono apocalíptico adoptado recientemente en la filosofia, México, Siglo XXI editores, 2006). La pregunta por el fin del mundo es un asunto crucial en una época que se caracteriza tanto por el despliegue de catástrofes reales como por las reiteradas representaciones de la catástrofe (V. Flusser, "Zukunft oder Ende”, en R. Maresch, (ed.), Zukunft oder Ende. Standpunkte-Analysen-Entwürfe, Viena, Boer, 1993, pp. 457-461, aquí p. 458). Estas cuestiones no se refieren tanto a cuándo el mundo va a terminar en realidad (aunque los riesgos militares, económicos y ecológicos convierten esta pregunta en algo relevante), sino que se asume igualmente la pregunta por nuestra fascinación particular por pensar los finales de manera violenta. Este asunto fue analizado ampliamente por Derrida en su famosa conferencia de 1984 en la Universidad de Cornell, en la cual el filósofo quería mostrar la relación estrecha entre el sentimiento apocalíptico gestado por la posibilidad de una guerra nuclear y la deconstrucción de la verdad como voluntad de poder (J. Derrida, "No apocalypse, not now. A toda velocidad, siete misiles, siete misivas", en Anthropos. Revista de documentación científica de la cultura 13, 1989, pp. 62-86, aquí, p. 85). Entre los diversos libros que abordan este asunto, queremos resaltar los editados por los profesores Malcolm Bull (1995) y Richard Dellamora (1996) que abordan de manera expresa este asunto revisando el trabajo de Jaques Derrida y mostrando a la vez la pertinencia de un análisis detenido de este problema (M. Bull, (ed.), Apocalypse Theory and the Ends of the World, Oxford, Blackwell, 1995. R. Dellamora (ed.), Postmodern Apocalypse: Theory and Cultural Practice at the End, Philadelphia, University of the Pennsylvania, 1996). El texto editado por Bull reúne una serie de ensayos de los escritores más conocidos sobre temas apocalípticos: Norman Cohn, Frank Kermode, Bernard McGinn, Marjorie Reeves y Edward Said, entre otros. En este libro se muestra no sólo la extraordinaria persistencia y variedad del pensamiento apocalíptico y su lugar en la cultura europea, sino también su estrecha conexión con las preguntas sobre el despliegue del poder político en el mundo contemporáneo. Sin duda, es un error creer que la temática apocalíptica es un simple asunto marginal en nuestro pensamiento contemporáneo, que supuestamente ha superado el nihilismo de finales del siglo XIX. En efecto, no se puede considerar que la representación apocalíptica es un asunto del pasado y que como tal no tiene nada que ver con el entusiasmo por la reconstrucción imaginativa de lo que sería la destrucción final del mundo. Por esta razón, para Kermode, el pensamiento apocalíptico no 
Ante la magnitud de estos acontecimientos, Heidegger emprende un camino en el pensar que puede ser asumido como una cierta estrategia dialógica del arte de sobrevivir en sentido blumenbergiano, pues aquí el espectador apartándose de la indignación frente a la catástrofe de la guerra busca asimilar en la distancia el sentido del sacrificio. En estas tres conversaciones, que integran el volumen editado por Ingrid Schüßler en 1995 con el nombre genérico de Feldweg-Gespräche ${ }^{5}$, se busca abrir el espacio a un otro pensar o esencia futura del pensar. Este pensar proviene de una mirada meditativa frente a lo pavoroso desplegado en el fenómeno de la guerra.

A través del diálogo meditativo, Heidegger busca mostrar que el pensamiento enraizado en la ciencia y en la cotidianidad dominada por la voluntad de saber se hunde en una fractura más abismal y destinal, desplegando con ello sus nefastas consecuencias destructoras o negadoras del ser humano. En su debilitamiento la forma habitual del pensamiento filosófico no puede empero ofrecer un espacio de apertura que anuncie lo venidero, intensificando con ello el rumbo histórico de la destrucción. En medio de esta fractura, la experiencia del dolor es ahora la que abre un nuevo sendero del pensar, pues nos pone no ante la fuerza del concepto discursivo, sino ante "un caso de inconceptualidad (Unbegrifflichkeit)".

se reduce esencialmente a la ansiedad "existencial" que cada uno de nosotros siente con respecto a su propio fin, su propia muerte. En nuestra época marcada por los genocidios y los temores legítimos de tecnologías destructivas y deshumanizadoras, tal énfasis en la relación del individuo con la muerte es, ciertamente, insuficiente para hacer frente a los impulsos apocalípticos de la modernidad y la posmodernidad. En este contexto, el trabajo de Christopher Norris, presentado en el libro editado por Dellamora, realiza un estudio muy sugerente del análisis de la retórica apocalíptica utilizada por los teóricos postestructuralistas, con especial atención en Derrida. Aquí Norris quiere señalar el "doble gesto" implícito en el lenguaje apocalíptico de Derrida, pues resulta imposible erradicar el tono apocalíptico de la deconstrucción derridiana que asume la terminología propia de la ilustración; pero el giro dado por el argelino a esta terminología funciona, más bien, como una estrategia apocalíptica para romper las intenciones moralizantes y políticas de la terminología de la política moderna. Nosotros en el presente trabajo consideramos esta estrategia en su sentido metaforológico. Es decir, señalaremos pues que el gesto que enmarca el alcance de estas manifestaciones apocalípticas sólo se puede comprender "gracias al truco de trabajar con la falta de claridad" (H. Blumenberg, Ein mögliches Selbstverständnis, Stuttgart, Philipp Reclam, 1997; La posibilidad de comprenderse. Obra póstuma, Madrid, Editorial Síntesis, 2002, p. 37), pues sólo de este modo se podría interpretar lo que vendría después del final de los tiempos.

${ }^{5}$ Las tres conversaciones que hacen parte de este volumen son las siguientes: 1- A $\gamma \chi \imath \beta \alpha \sigma i \eta$ Ein Gespräch selbstdritt auf ein Feldweg zwischen einem Forscher, einem Gelehrten und einem Weisen. 2- Der Lehrer trifft den Türmer an der Tür zum Turmaufgang. 3-Abendgespräch in einem Kriegsgefangenenlager in Rußland zwischen einem Jüngeren und einem Älteren.

${ }^{6}$ H. Blumenberg, Schiffbruch mit Zuschauer. Paradigma einer Daseinmetapher, Frankfurt, Suhrkamp, 1979, p. 87; Naufragio con espectador. Paradigma de una metáfora de la existencia, Madrid, Visor, 1995, p. 97. El sentido de esta apertura abierta en la experiencia del dolor lo podemos encontrar tematizado en los siguientes trabajos, entre otros: E. Scarry. The Body in Pain. The Making and Unmaking of the World, New York, Oxford University Press, 1985. E. Ocaña, Sobre el dolor, Valencia, Pre-Textos, 1997. M. González (ed.), Filosofía y dolor, Madrid, Tecnos, 2006. J. Moscoso, Historia cultural del 
En el texto de Heidegger en cuestión el punto de partida de esta apertura es justamente la inquietud de un joven prisionero que busca algo curativo frente a la devastación generalizada que ve por doquier. Pero esta búsqueda se enmarca en el contexto más amplio de la magnitud histórica de lo acontecido. Por esta razón, el viejo profesor interpela al joven para que reconozca aquello curativo que se abre en su herida, pues si bien se encuentra profundamente abatido, aún no está en él todo quebrado. Como vemos, se presenta aquí una ambivalencia que determina el rumbo del diálogo. Este diálogo busca reconocer la herida profunda de nuestra época que se muestra en lo individual. Pero no se trata sólo de una herida particular de un individuo, pues a lo largo del diálogo se habla también tanto de la herida "en ti" como de la herida "en nosotros"?

Con la tematización de la dimensión histórica de la herida entra en juego la pregunta por la devastación del mundo, pues ella condensa de manera cruda la desgracia escenificada en la guerra. Aquí el tema de la devastación es asumido por Heidegger en su dimensión histórica. Por esta razón, el filósofo señala que si bien el mundo celebra el fin de la guerra, aún no se reconoce "que ya desde hace siglos el mismo mundo había sido vencido por su propia rebelión"». En este sentido, podemos decir que lo histórico puntual se encuentra indicado aquí como un elemento que se extiende en un proceso histórico más amplio y que se relativiza, de este modo, la unicidad que posee como evento histórico concreto. Para Heidegger, la guerra no es simplemente un acontecimiento histórico más, sino la máxima condensación de la negatividad de la historia como evento de destrucción y desolación del mundo, pues como él mismo señala "la devastación estaba ya en obra, antes de que comenzara la destrucción"".

Ya antes en 1930 el mismo Heidegger había señalado que hay una tendencia histórica en la forma habitual de comprender nuestro estar en el mundo que nos ha convertido en insensibles frente a la existencia, ya que hoy todos pasan de largo aquello que, incluso, se presenta como monstruoso. Podríamos decir que ya casi nada nos provoca terror. Por esta razón, el filósofo pregunta:

"¿Qué sucede con nuestra existencia cuando un acontecimiento tal como la guerra mundial en lo esencial ha pasado de largo ante nosotros sin dejar ningún rastro? ¿No es eso una señal de que quizá ningún acontecimiento, por muy grande que sea, es

dolor, Madrid, Santillana, 2011. L. F. Cardona, Mal y sufrimiento humano. Un acercamiento filosófico a un problema clásico, Bogotá, Editorial Pontificia Universidad Javeriana, 2012. L. F. Cardona (ed.), Filosofia y dolor. Hacia la autocomprensión de lo humano, Bogotá, Editorial Pontificia Universidad Javeriana, 2014.

${ }^{7}$ M. Heidegger, Feldweg-Gespräche, Frankfurt, Klostermann, 1995, p. 207.

${ }^{8}$ Ibidem, p. 240.

${ }^{9}$ Ibidem, p. 220. 
capaz de asumir esta tarea, si el hombre previamente no se ha puesto en camino para ser despertado?"10.

Ahora bien, para que un acontecimiento histórico nos conmueva realmente, se requiere que nos hayamos previamente echado "en cada caso la existencia a las espaldas"11. Y más tarde en sus lecciones de invierno de 1951 y 1952, Heidegger busca encarar la dinámica interna de la devastación del mundo, señalando que no podemos reducirla simplemente a la mera destrucción, pues "la desertización no es un simple cubrir de arena. La desertización es el rápido curso de la expulsión de Mnemosyne"12. Para contextualizar el sentido de esta indicación, profundamente enigmática, Heidegger apela a los siguientes versos de un borrador de Hölderlin de su himno a Mnemosyne de 1804:

"Un signo somos, indescifrado.

Sin dolor somos y en tierra extraña

casi perdemos el habla"13.

¿Qué significa esta caracterización metafórica de la devastación? Según la indicación de Hölderlin, el hombre es un signo indescifrado (bedeutungslos) ${ }^{14}$, pues al parecer no es un signo para otra cosa más que para sí mismo, es decir, se trata de un signo que permanece abierto sin ninguna otra referencia más que a sí mismo. Pero el propio hombre no puede saber en última instancia nada sobre sí mismo. Recordemos que todo signo deber ser interpretado como algo que remite a otra cosa distinta, en la medida que transita hacia algo distinto de sí mismo o simplemente lanza fuera de sí mismo ${ }^{15}$. Sin embargo, un signo no puede determinarse desde sí mismo, pues no pa-

10 M. Heidegger, Die Grundbegriffe der Metaphysik. Welt-Endlichkeit-Einsamkeit, Frankfurt, Klostermann, 1983; Los conceptos fundamentales de la metafisica. Mundo, finitud y soledad, Madrid, Alianza, 2007, §38, p. 221.

${ }^{11}$ Ibidem, p. 211.

${ }^{12}$ M. Heidegger. Was heisst denken?, Tubinga, Max Niemeyer Verlag, 1954, p. 11; ¿Qué significa pensar?, Madrid, Editorial Trotta, 2005, p. 28.

${ }^{13}$ F. Hölderlin, Sämtliche Werke und Briefe, Darmstadt, Wissenschaftliche Buchgesellscahft, 1998, tomo I, p. 436.

${ }^{14}$ En este punto es necesario tener en cuenta que para Hölderlin el hombre es siempre un signo indescifrado y, por ello, debe emprender el camino de regreso a su auténtica morada. Este camino de regreso no es otro más que "el camino poético del recuerdo de su origen inmodificable" (B. Philipsen, "Gesänge (Stuttgart, Hamburg)”, en J. Kreuzer (ed.), Hölderlin Handbuch. Leben-Werk-Wirkung, Stuttgart, J. B. Metzler Verlag, pp. 375-179, aquí p. 376).

${ }^{15}$ En el parágrafo 59 de la Crítica del juicio Kant señala el procedimiento de la remisión propia del símbolo como "la transferencia de la reflexión sobre un objeto de la intuición a un concepto totalmente diferente, al que quizá nunca puede corresponder directamente una intuición" (I. Kant. Kant's gesammelte Schriften. Werke, Briefe, Opus postumum, Vorlesungen, Ausgabe der Akademie der Wissenschaften, Berlín, Walter de Gruyter, 1900, tomo V, p. B353; Crítica del discernimiento, Madrid, 
rece sensato que sólo pueda remitir hacia sí mismo. Por esta razón, cuando Hölderlin señala que el hombre es un signo indescifrado, Heidegger lee esta formulación del modo siguiente: el Dasein humano no puede ser el punto de mira de todos los signos, pues no es la medida hacia la cual todo remite y en la cual todo termina siendo en su medio.

Ahora bien, las palabras devastación (Verwüstung) y desierto (Wüste) son con frecuencia asumidas en el contexto bíblico en el que son aquí retomadas por Heidegger. Por ejemplo, en el Evangelio de Marcos podemos encontrar un lugar significativo para comprender la magnitud de la $\varepsilon \rho \eta \dot{\mu} \mu \omega \sigma \eta$, es decir, devastación. Se trata de la enseñanza sobre la desolación del mundo y el temor del tiempo final. Recordemos que al salir del templo un discípulo elogia las producciones del hombre, señalando de manera particular la construcción del templo. Aquí se señala que esto es realmente tan solo piedra, es decir, un estado falaz que el mal tapará, pues estos bellos edificios serán "de tal modo destruidos, que no quedará piedra sobre piedra"

Es decir, el mal se incrementa y debe siempre incrementar su poder más y más, para que así pueda finalmente emerger lo salvador. En este sentido, es propio de los horrores del fin del mundo que les sucedan "un nuevo cielo y una nueva tierra" Parece entonces que la guerra y la destrucción deben darse para que la justicia de Dios pueda finalmente imperar, pues "cuando vean ustedes que suceden estas cosas, sepan que El hijo del hombre está cerca, a la puerta"18. En medio del mal se hace entonces necesario estar atento a aquello que permanece aún vivo frente a las falacias que se quieren hacer pasar por lo salvador, pero que realmente no lo son. Se debe pues estar vigilante para atender a la verdadera epifanía de lo salvador. ¿Cómo podemos reconocer estas falacias? ¿Qué rasgos nos permiten comprenderlas en lo que realmente son?

Para evitar tomar lo falso por verdadero, podemos ahora recordar la distinción entre el hombre que está despierto y el que está dormido, pues de este modo apreciamos el verdadero horror de la devastación. Como dice el texto bíblico: “[...] pero quien resista hasta el final se salvará. Cuando vean que el execrable devastador está donde no se debe (entiéndelo, lector,), entonces los que estén en Judea, que huyan a la sierra" ${ }^{19}$. ¿Qué es lo que realmente se está aquí señalando? El horror de la devastación significa el surgimiento del anticristo, del hombre como Dios, esto es, la comparecencia de la salvación aparente pero que no es precisamente lo salvador, sino el incremento de la desgracia más profunda.

\footnotetext{
Alianza editorial, 2012, p. 501). Para Blumenberg, aunque Kant no utilice aquí la expresión metáfora, lo cierto es que está mostrando el modelo funcional pragmático que caracteriza a la metáfora como transporte de la reflexión.

${ }^{16}$ Mc. 13, 2.

${ }^{17}$ H. Blumenberg, La posibilidad de comprenderse, op. cit., p. 37.

${ }^{18}$ Mc. 13, 29.

${ }^{19}$ Mc. 13, 13-14.
} 
Un motivo concreto de esta desgracia era, para el evangelista, la colocación de una imagen del hombre en el centro del templo, una estatua del hombre como Dios en el santísimo. Pero esto era tan sólo un primer indicio de algo que más tarde se iba ampliar de manera histórica en su decurso destinal. Esta imagen corresponde, en efecto, al autoposicionamiento del hombre, esto es, al levantamiento del hombre a aquel lugar que antes ocupaba Dios. Nos topamos aquí con la propia rebelión del hombre. En este sentido, podemos hablar de un gran horror desolador, cuando lo que emerge es producto de aquella situación en la cual el hombre mismo se ha hecho Dios. En la Carta segunda de San Pablo a los Tesalonicenses, podemos encontrar precisado el alcance de este horror producto de la autoposición del hombre-Dios, cuando se advierte que aquel que se ha levantado contra todo aquello que Dios y el culto divino ordenan, aceptando poner al hombre en el templo en lugar de Dios y haciéndose pasar por Él, ha caído ya en la perdición: "El hombre destinado a la ruina, el que se enfrentará y se pondrá por encima de todo lo que se llama Dios o es objeto de culto, hasta instalarse en el templo de Dios, proclamándose él mismo Dios"20.

Así pues, el guardia que no duerme en la realidad aparente debe cuidar de la pretensión de lo divino, apartándose de los dioses falsos que se hacen pasar como Dios para despistarlo, porque, como dice Marcos, "saldrán mesías falsos y falsos profetas, y realizarán señales y prodigios que extraviarían, si fuera posible, a los elegidos" 21 . En este autoposicionamiento del hombre el mundo es un mundo del extravío y de la apariencia, esto es, un mundo de la destrucción de lo divino y de su sustitución por la presencia de dioses aparentes. Por esta razón, el creyente debe esperar a aquel Dios cuya salvación viene sin preparación. Podemos decir ahora que la devastación consiste entonces en que el mundo se ha hecho vacío y desierto ante el aliento de lo sagrado que se distancia de los hombres por causa de la autoposicionamiento del hombre como Dios. Es decir, la dimensión propia de lo sagrado se ha levantado y con ello se deja al hombre solo consigo mismo y con sus desmedidas pretensiones.

En este contexto, podemos afirmar que una característica fundamental del mundo del extravío y del engaño consiste en que el hombre se ha convertido en un signo que no puede ya ser descifrado. Pero más allá de los esfuerzos de autocomprensión, que lo lanzan hacia sí mismo, lo cierto es que el hombre debe remitirse también a una relación con lo sagrado. Aquel que está extraviado cree poder escapar de su ausencia de significado buscando encerrarse en un círculo y convirtiéndose tan sólo en un signo para sí mismo. Pero no reconoce que él se pone realmente como un signo indescifrado. Por esta razón, el hombre está lanzado a emprender una rebelión contra lo divino, porque sencillamente no soporta la impotencia que significa su condición de errancia. Podemos empero anotar que esta forma de hablar está, ciertamente, impregnada de un tono apocalíptico.

\footnotetext{
${ }^{20} 2$ Tes. $2,4$.

${ }^{21}$ Mc. 13, 22.
} 
Sin embargo, lo que con ello se cuestiona es si realmente el hombre puede llegar a ser una imagen viva de sí mismo a partir de su propia condición. Cuando el hombre no es más que el fiel reflejo del Dios creador de la tradición judeocristiana, lo que resulta apenas obvio es su deseo de convertirse en una imagen viva de sí mismo:

\begin{abstract}
"La única conclusión reza ante todo para el pensar según la historia del ser (Seyn): el hombre de ninguna manera es retrato fiel de otro, sino de la más propia y destacada esencia (en virtud de la referencia al ser-Seyn): la singularidad de su esencia no significa egoísmo de la obstinada posición esencial, sino pertenencia a lo más singular, que como tal no conoce a ningún otro semejante, al ser (Seyn). El ser-ahí coasume la historia de la fundación de la incomparabilidad, según la historia del ser, de la esencia humana"'22.
\end{abstract}

Por esta razón, el cristianismo ha sido para Heidegger un efectivo cómplice del surgimiento del acontecimiento histórico de la devastación. Es decir, el hombre comprendido de esta manera no tenía por qué permanecer indescifrado, si realmente hubiese logrado orientar su existencia hacia Dios, esto es, si se hubiese proyectado a la lejanía de lo in-mundo. Sólo a Dios se puede el hombre fijar gracias a su lugar determinado en una proyección final que se muestra y prueba como un ascenso consistente.

Pero dado que Dios se pone cada vez más lejos, refugiándose en un mundo distante, se le asume también como el origen del signo, convirtiéndolo en algo por encima del hombre y al mismo tiempo distante de él. Recordemos empero que un signo que es sólo signo de sí mismo es, en efecto, un sinónimo de la ausencia de un verdadero significado, esto es, de la pérdida del signo como tal. Esta situación expulsa al hombre del ámbito de Mnemosyne.

\title{
2. El destierro de Mnemosyne
}

Retomemos ahora las consideraciones heideggerianas sobre el destierro de Mnemosyne, pues así podemos resaltar el significado del horror de la devastación histórica acaecida en Occidente. Como lo indicamos en el punto anterior, este destierro significa borrar la ausencia de explicación del signo. Pero esta interpretación es todavía imprecisa, pues es apenas evidente que un destierro no lleva consigo necesariamente una extinción plena de todo lo vivo. La devastación como expulsión de Mnemosyne significa, más bien, el no percatarse del carácter de signo de la vida humana. Por esta razón, el hombre es incapaz de soportar la propia ausencia de significado, buscando sustituir su vacío. En este contexto, podemos afirmar que la cusa de este destie-

\footnotetext{
${ }_{22}^{22}$ M. Heidegger, Besinnung, Frankfurt, Klostermann, 1997, p. 328; Meditación, Buenos Aires, Editorial Biblos, 2006, p. 281.
} 
rro es el autoposicionamiento metafísico del hombre que se despliega en la historia acaecida del nihilismo, pues este posicionamiento abre un espacio para que se dé la experiencia modificada de lo divino y salvador. Así pues, si Mnemosyne es tan sólo desterrada pero no por ello aniquilada, es decir, si todavía está dada la posibilidad para retroceder un paso en dicha devastación metafísica, pues es aún posible "un nuevo cielo y una nueva tierra", podemos preguntar entonces: ¿cómo puede surgir lo salvador en medio de este desierto? Esto es, ¿cómo es posible aún la serenidad de lo curativo en el desierto?

Para atender a estas preguntas, debemos recordar que la expulsión de Mnemosyne significa deponer la presencia de lo salvador en medio de la desolación. Obviamente, debemos tener presente también que en nuestra época, marcada por el nihilismo extremo y por la superficialidad de las formas históricas de asumir la vida, ya no hay nada que pueda ser considerado como algo externo. Ahora todo se encuentra determinado por "la interna conexión entre trabajo y dolor"23.

En el presente trabajo hemos querido señalar cómo Heidegger busca un punto de vista filosófico para lograr una determinación hermenéutica del concepto devastación. La diferencia fundamental entre el concepto tradicional de devastación y su comprensión filosófica se puede determinar del siguiente modo: en los análisis heideggerianos del presente se pone en evidencia la situación paradójica de la existencia histórica del hombre contemporáneo. Parece ser que los hombres no nos hemos dado cuenta del transcurso histórico de la devastación. Es decir, cuando hablamos de ella hacemos como si fuéramos conscientes de su verdadera dimensión destinal, pero al mismo tiempo nos ponemos fuera de su alcance. Con esto se produce una cierta

\footnotetext{
${ }^{23}$ M. Heidegger, Wegmarken, Frankfurt, Klostermann, 1976, p. 404; Hitos, Madrid, Alianza editorial, 2001, p. 328. La conexión entre trabajo y dolor es uno de los temas central abordados por Jünger no sólo en su texto Sobre el dolor, sino ante todo en El trabajador. Mostrando cómo el trabajo ha inundado toda forma de vida, Jünger anota que "el trabajo no es, por tanto, actividad en general, sino que es la expresión de su ser especial que intenta llenar su espacio propio, henchir su tiempo propio, cumplir sus leyes propias. De ahí que el trabajo no conozca nada que se le oponga fuera de sí, no conozca ninguna antítesis; se parece al fuego, el cual devora y transforma todas las cosas susceptibles de combustión y al que sólo puede disputarle el terreno su propio principio, es decir, un contrafuego. El espacio del trabajo es ilimitado, de igual manera que la jornada de trabajo abarca veinticuatro horas. Lo contrario del trabajo no es el caso el descanso o el ocio; no hay, desde este ángulo de visión, ninguna situación que no sea concebida como trabajo. Como ejemplo práctico de esto cabe mencionar el modo en que hoy se entregan los seres humanos a sus esparcimientos. Estos esparcimientos, o bien exhiben, como ocurre en el deporte, un patentísimo carácter de trabajo, o bien representan dentro del trabajo un contrapeso coloreado de juego, como ocurre en las diversiones, en las festividades técnicas, en las estancias en el campo, pero de ninguna manera representan lo contrario del trabajo. Con esto guarda relación el absurdo creciente de los domingos y días festivos de viejo estilo - de los domingos y días festivos de ese calendario que corresponde cada vez menos al ritmo modificado de la vida" (E. Jünger, Der Arbeiter: Herrschaft und Gestalt, Darmstadt, Klett-Cotta, 2007; El trabajador. Dominio y figura, Barcelona, TusQuets Editores, 1993, 90-91). El trabajo ha devenido en estilo de vida que inunda todo en nuestra vida moderna, incluso, la diversión y el sufrimiento.
} 
neutralización de su verdadero alcance histórico, al omitir que lo decisivo en nuestro presente radica en el hecho de que ya no hay nada fuera de la devastación misma: todo lo inunda. A su vez, esta comprensión impide que se interprete adecuadamente el desierto como una especie de amplitud que va más allá del espacio de lo inmediatamente amenazante.

Ahora bien, "el desierto es lo inhabitado: la extensión olvidada del desamparo de toda vida" ${ }^{24}$. Es decir, se trata de una desolación efectiva de toda vida y de todo poder renacer, pues parece que ya no es posible "un nuevo cielo y una nueva tierra". En este sentido, no hay ahora ninguna otra posibilidad a la extensión vacía del desierto que contrarreste su crecimiento, sino sólo un permanente deshacerse en una uniformidad desconcertante. Así pues, la amplitud como tal parece que ya no puede ser por sí misma curativa, pues puede causar también un estrechamiento radical de sus posibilidades destinales. Es decir, la expansión del desierto es, en el fondo, una situación subsidiaria. Pero lo verdaderamente decisivo consiste en preguntar por aquello que, si bien no está indicado de manera expresa en nuestra forma habitual de hablar de la devastación, realmente la realiza de manera imperceptible. Sin duda, esto es algo que debemos tener en cuenta, si queremos examinar con mirada atenta el crecimiento desolador de la devastación de la tierra.

La devastación no expresa, en primer lugar, un mero quedar desierto que se incrementa de modo sucesivo y que pasa ante nuestros ojos como si se tratase de algo que tan sólo se observa. Ella implica, más bien, una desolación más profunda que ya desde un comienzo acontece en la propia vida de un modo imperceptible. Recordemos que en el texto que estamos comentando, Heidegger asume el discurso de "una devastación que se profundiza y que es un ser que avanza, pero que nuestra reflexión regresa siempre de nuevo a ella" ${ }^{25}$. Pero con esto no podemos aún reconstruir con facilidad cuál es este período común más originario presente en todo recorrido histórico de la humanidad. Si la devastación es el mal que se despliega de modo histórico y muestra en cada momento de su despliegue el efecto de una enfermedad más profunda, podemos entonces señalar en cada uno de sus momentos históricos concretos la presencia de una infección que se expande de manera más o menos sutil. Obviamente, esta enfermedad tiene, para Heidegger, un largo período de incubación antes de su plena manifestación histórica en la Modernidad y, en particular, en la guerra.

Siguiendo esta pauta hermenéutica, podemos ahora señalar una segunda indicación de la virulencia de esta manifestación histórica. Recordemos que el mismo Heidegger habla también de que "la historia europea de los últimos tres siglos y medio nos dice qué hicieron los hombres cuando desencadenaron a la tierra de su sol" ${ }^{\prime 2}$. Este período no es otro más que el de la irrupción del nihilismo, cuando todo

\footnotetext{
${ }^{24}$ M. Heidegger, Feldweg-Gespräche, op. cit., p. 212.

${ }^{25}$ Ibidem., p. 207.

${ }^{26}$ M. Heidegger, Holzwege, Frankfurt, Klostermann, 1984, p. 241; Caminos de bosque, Madrid,
} 
el horizonte fue borrado y cuando la totalidad de lo ente fue absorbida dentro de la inmanencia de la subjetividad. Por esta razón, podemos hablar de un momento en el que la devastación comenzó como un proceso no consciente. Este proceso se levantó desde la verdad como certeza en la que el propio representar humano se quería asegurar a todo precio frente al insoportable dolor del mundo:

"La devastación de la tierra empieza como proceso querido, pero que en su esencia no es sabido ni se puede saber, un proceso que se da en el tiempo en el que la esencia de la verdad se cerca como certeza en la que lo primero que se asegura a sí mismo es el representar y el producir del hombre"27.

Como lo señala esta cita, nuestro languidecer presente tiene su raíz más profunda en la aspiración de alcanzar la incondicionalidad humana absoluta. Como sucede con un virus, su verdadero potencial destructivo pasó desapercibido en los períodos iniciales de larga incubación y sólo se reconoció como tal, cuando se desveló con toda su fuerza ante nuestros ojos, pues sólo así mostró la cólera que desde un comienzo incubaba. Es decir, el despunte del largo período histórico de la metafísica no sólo comienza con el giro moderno de Descartes. La Antigüedad y la Edad Media pertenecen también, como un objeto de anamnesis, a este proceso de devastación, en la medida que son la verdadera prehistoria de la enfermedad que se nos presenta hoy con toda su virulencia. Es decir, el giro moderno es, por un lado, una cesura dado que marca el inicio de la infección, pero, por otro lado, no es tan sólo una simple fractura, ya que el virus estaba antes presente en la historia del ser, pero aún no se había manifestado como tal con todo su poder destructor.

Lo verdaderamente alarmante consiste entonces en que la propia época presente sabe muy poco de la amenaza que conlleva este proceso histórico. Es decir, la propia devastación trae consigo el despliegue descomunal de una cierta insensibilidad para el dolor y para la miseria, incrementando así la desolación y devastación. Esta insensibilidad se vincula al hecho de que el hombre en medio de la catástrofe aún no sabe lo que significa propiamente la devastación y, por ello, busca cambios de contrapeso

Alianza editorial, 1998, p. 194. Aquí Heidegger sigue de manera expresa a Nietzsche, cuando en la Gaya ciencia el loco grita: “¿Quién nos prestó la esponja para borrar el horizonte? ¿Qué hicimos cuando desencadenamos la tierra de su sol? ¿Hacia dónde caminará ahora? ¿Hacia dónde iremos nosotros? ¿Lejos de todos los soles? ¿No nos caemos continuamente? ¿Hacia adelante, hacia atrás, hacia todos los lados, hacia todas las partes? ¿Acaso hay todavía un arriba y un abajo? ¿No erramos como a través de una nada infinita? ¿No nos roza el soplo del espacio vacío? ¿No hace más frío? ¿No viene siempre noche y más noche? ¿No tenemos que encender faroles a mediodía? ¿No oímos todavía el ruido de los sepultureros que entierran a Dios? ¿No nos llega todavía el olor de la putrefacción?” (F. Nietzsche, Werke, Darmstadt, Wissenschaftliche Buchgesellschaft, 1969, tomo 3, p. 127).

${ }^{27}$ M. Heidegger, Vorträge und Aufsätze, Pfullingen, Neske, 1985, p. 95; Conferencias y artículos, Barcelona, Odos, 1994, p. 89. 
que pudiesen modificar el decurso histórico de estos acontecimientos, como si esto dependiera de su voluntad y acción. En esta búsqueda, "la futilidad del intento de cambiar a los sujetos favorece la evidencia de que existe aún la posibilidad de un gran cambio, de que, por una misteriosa fatalidad, la totalidad de los objetos se transforme desde la raíz y con ello también se muden las condiciones del comportamiento de los sujetos"28.

Más allá de la propia crudeza de la guerra, la devastación que vemos por doquier permanece en el plano de lo superficial frente a un proceso mucho más turbulento y feroz, que avanza a partir del deseo humano de convertirse en lo incondicionado de todo lo existente. Así pues, Heidegger caracteriza la guerra como una destrucción, ya que su tesis fundamental consiste en señalar que la devastación había sido puesta en obra antes de que comenzara propiamente la destrucción, que hoy vemos condesada en la guerra. Es decir, lo que antecede a la devastación no se puede deducir sólo del pavor de la guerra. Ver los asuntos históricos bajo la lente de la responsabilidad particular es, sin duda, una gran ingenuidad. En un tono decididamente apocalíptico, podríamos ahora preguntar: ¿"qué podrían ser un nuevo cielo y una nueva tierra, después de que el antiguo cielo y la antigua tierra les hayan salido claramente tan mal a su Creador"? ${ }^{29}$.

Una "movilización total" ${ }^{30}$, en el sentido de Jünger, con la consecuencia de una destrucción igualmente total, no es lo más inquietante del fenómeno de la devastación. Lo verdaderamente decisivo es, más bien, aquello que ha guiado a dicha movilización, sin que esto haya sido percibido aún de un modo claro. En efecto, al igual que Heidegger, Jünger señala que el mundo del paisaje del taller está desierto, pues la

\footnotetext{
${ }^{28}$ H. Blumenberg, La posibilidad de comprenderse, op. cit., p. 38.

${ }^{29}$ Ibidem., p. 37.

${ }^{30}$ Ernst Jünger muestra cómo la catástrofe de la guerra moderna consistió históricamente en que el genio de la guerra se compenetró perfectamente con el espíritu del progreso. Mostrando la diferencia entre el modelo monárquico de la movilización parcial, en la que el monarca moviliza tan sólo los combatientes y los equipamientos bélicos participan de manera abstracta del espíritu, del dinero y del pueblo, Jünger caracteriza el modelo moderno de la movilización total indicando "como la imagen de la guerra en cuanto acción armada va penetrando cada vez más en la imagen más amplia de un gigantesco proceso de trabajo; junto a los ejércitos que se enfrentan en los campos de batalla surgen los nuevos ejércitos del tráfico, del abastecimiento, de la industria de armamento -el ejército del trabajo en general. En la fase final de la última guerra, que ya apuntó en sus postreros momentos, no se efectúa ningún movimiento -ni siquiera el de una trabajadora doméstica en su máquina de coser- que no encierre una aportación bélica al menos indirecta. Donde de modo más perceptible apunta el alba de la edad del trabajo es quizás en ese alistamiento absoluto de la energía potencial; tal alistamiento transforma en fraguas de Vulcano los estados industrializados combatientes y hace de la guerra mundial un fenómeno histórico de significado superior al de la Revolución Francesa. Para desplegar energías de tal envergadura ya no es suficiente con equipar el brazo armado - se requiere unos equipamientos que lleguen hasta el tuétano más íntimo, hasta el nervio vital más fino. Hacer realidad estos equipamientos es la tarea de la movilización total" (E. Jünger, Sobre el dolor seguido de La movilización total y Fuego y movimiento, Madrid, TusQuets, 1995, pp. 97-98).
} 
movilización que aquí se emprende es realmente "una movilización destructora"31. Su análisis indica tan sólo el señalamiento, en sentido heideggeriano, de una herida del tiempo, pero no da el diagnóstico adecuado de una enfermedad que caracteriza a la historia acaecida del hombre en cuanto historia del nihilismo. Pero con esta indicación no se ha comprendido aún la verdadera esencia de la enfermedad.

Para Heidegger, la movilización total sería entonces una consecuencia del abandono originario del ser, pues no es más que "el puro poner-en-movimiento y el ahuecamiento de todos los contenidos vigentes de la formación todavía existente. La primacía del proceder y de la organización de la totalidad en la puesta al servicio de las masas"32. Que surja en esta movilización una determinación del hombre es tan sólo una consecuencia negativa de este acaecer, pero nunca su meta final. Por esta razón, resulta necesario que el devenir histórico de dicha movilización sea comprendido en su ser esencial ${ }^{33}$, es decir, en su carácter verdaderamente destinal. Así pues, la devastación no es de ningún modo algo desierto que se incrementaría posteriormente más y más, ni un simple hacer vacío de un existente. Más bien, es el ensamblaje de un socavamiento asegurado de cada posibilidad de toda decisión y de todo espacio de decisión. En el despliegue histórico de la Modernidad surge un socavamiento supremo y un empequeñecimiento por falta de sentido:

"El empequeñecimiento metafísico del mundo engendra un excavamiento del hombre. La referencia al ente como tal pierde en éste y como éste toda meta, la referencia como comportamiento del hombre se refiere no más que a sí misma y a lo planificado de su realización. El sentir del sentido no siente más que el sentir; así el sentido mismo se convierte en objeto del goce" ${ }^{n 4}$.

Nietzsche ya había caracterizado antes este proceso como algo subterráneo, como aquello que socava, esto es, que realiza un trabajo de derrumbamiento. La interpretación de este socavamiento implica articular tres notas fundamentales que deben

\footnotetext{
${ }^{31}$ E. Ocaña, Más allá del nihilismo. Meditaciones sobre Ernst Jünger, Murcia, Universidad de Murcia, 1993, p. 238. La fuerza de esta movilización es el verdadero dispositivo nihilista que se pone en juego justamente en la guerra (U. Bröckling, "Die totale Mobilmachung (1930)", en M. Schöning (ed.), Ernst Jünger. Handbuch. Leben-Werk-Wirkung, Stuttgart, Metzler Verlag, 2014, pp. 101-105, aquí p. 103).

${ }^{32}$ M. Heidegger, Beiträge zur Philosophie. (Vom Ereignis), Frankfurt, Klostermann, 1989, §74, p. 143; Aportes a la filosofía. Acerca del evento, Buenos Aires, Editorial Biblos, 2003, p. 126.

${ }_{33}$ Para Heidegger, no basta con que se reconozca como existente la movilización total, sino que se hace necesario comprenderla desde una posición más esencial. La esencia de la era debe ser comprendida siempre y en cada momento a partir de la verdad del ser que reina en ella, "porque sólo así se experimenta al mismo tiempo aquello que es más digno de ser cuestionado y que soporta y vincula desde el fundamento a un crear en dirección al porvenir, dejando atrás a lo que está ahí para que la transformación del hombre se convierta en una necesidad surgida del propio ser" (M. Heidegger, Holzwege, op. cit., p. 89; en español, p. 79).

${ }^{34}$ M. Heidegger, Beiträge zur Philosophie, op. cit., §274, p. 495; en español, p. 390.
} 
ser ahora señaladas con precisión. Sólo así podemos comprender el alcance de la determinación metafórica de la devastación de la tierra. Puntualicemos esta determinación de la siguiente manera: 1) Este socavamiento indica la insensibilidad de este acontecimiento devastador, pues no siempre se muestra en él en primer plano aquello que está puesto en su superficie. 2) Con este socavamiento se señala también que nada puede prosperar en medio de una tierra así devastada, pues quedan destruidas todas las raíces para que se pueda abrir un "nuevo cielo y una nueva tierra". 3) Se indica con ello también que este socavamiento amenaza con expandirse sin límites hacia todo lo existente, cuando aparece como un desmoronamiento generalizado, es decir, si ya es demasiado tarde para sobreponerse a él.

Esta devastación permanece empero como realmente insensible frente a todo lo que se niega y ha sido mirado como mero abuso. Esto no se puede eliminar de modo inmediato, sino tan sólo por mediación de la esencia misma que está puesta en su existencia. Sin duda, se da aquí una situación paradójica, pues en su esencia se revela el carácter inasible del final. La obsesión por alcanzar el fin del mundo pone en evidencia una profunda incomprensión del orden de la creación, ya que "el hombre puede destruir mucho, cada día más, y puede destruir más de lo que jamás ha aportado para que las cosas duren; pero la creación, el universo de mundos y de soles, de esas innumerables oportunidades para que surja algo como él -si así hubiera estado dispuesto en esta creación divina-: este poder no lo tiene. De hecho, está ridícula, infinitamente lejos de tenerlo"35. Así pues, la desolación permanece firme a pesar del saber de su efecto socavador, incluso si se le reconoce como tal. En este sentido, podemos decir que cuando se descubre esta desolación, permanece todavía como no abolida, ya que debe tender a suprimirse ella misma, por decirlo así, desde sí misma.

¿Esto señala entonces que el socavamiento sería algo inmodificable sólo hasta que el primer hundimiento haya terminado de manera definitiva, pues para el advenimiento de un nuevo cielo y una nueva tierra se requiere pues que el antiguo cielo y la antigua tierra hayan resultado mal en el conjunto de la creación? Es decir, ¿no se puede eliminar el mal así comprendido? ¿Este mal debe aparecer de tal modo que al mismo tiempo se destruya a sí mismo? ¿Esta situación nos llevaría entonces a una cierta visión apocalíptica del presente, pues el mal se expandiría progresivamente hasta alcanzar él mismo su plena extinción? Para atender a estas cuestiones, debemos tener presente que hablar de la destrucción que enmarca el despliegue histórico de nuestro presente destinal implica, para Heidegger, hablar también de aquello salvador que se anuncia ya en medio de la devastación más extrema. ¿Cómo es esto entonces posible?

\footnotetext{
${ }^{35}$ H. Blumenberg, La posibilidad de comprenderse, op. cit., pp. 35-36.
} 


\section{Cantar la historia de la ira}

En su diálogo de 1946 Heidegger es consciente de que la guerra ha terminado, pero que todavía nada ha sido modificado. Al contrario, toda la devastación ocurrida ha encontrado ahora un momento histórico para su intensificación extrema. Frente a este hecho, podemos empero preguntar: ¿puede la experiencia de lo saludable indicar una posible curación desde sí misma a la herida del mal y gestar así un cambio en el proceso histórico de este recrudecimiento, de modo que se abra un nuevo cielo y una nueva tierra? O, más bien, ¿todo cambio nos está vedado?

Estas preguntas no pueden recibir, en efecto, una repuesta clara y sencilla, porque en tiempos de penuria la experiencia de lo salvador permanece cubierta por una esperanza que se difumina con su avance en una prolongación indefinida del tiempo ${ }^{36}$. Es decir, esta esperanza se retrotrae a la proyección de la "historia del ser". Pero en esta proyección nos topamos con una contradicción insalvable. En el marco de esta historia, Heidegger considera que "los sujetos no cambian porque -para que se pueda, por su parte, pasar por alto tal pasar por alto- les despoja totalmente de eficacia causal y la asigna a una esfera objetiva, que ya no es la Historia hecha por el hombre, sino la historicidad como ejercicio del arbitrio del ser. Ha de ser el ser el que cambia para que no necesiten cambiar los sujetos. Cosa que tampoco podrían hacer en absoluto y para lo cual sería totalmente inútil alegar buenas razones, como ya se ha experimentado y sufrido en la Historia" ${ }^{37}$.

En este contexto, es preciso recordar que la acentuación histórica del autoritarismo y de la tenacidad de una voluntad de poder desmedida trajo consigo no sólo la desolación de lo humano. Estas acentuación implicó también el crecimiento de la devastación y de sus efectos históricos que han oscurecido una vez más las huellas de lo salvador. Esta obstinación moderna de la malignidad de la herida abierta del mal es denominada por Heidegger "furia":

"Lo maligno es lo sedicioso que se basa en lo furioso, de modo que esto furioso esconde en cierto modo su ira, pero al mismo tiempo amenaza con ello permanente-

\footnotetext{
${ }^{36}$ Debido a esta prolongación infinita e indefinida, podemos ver que "por todas partes hay acción efectiva y en ninguna parte un hacer mundo del mundo, y sin embargo, aunque olvidado hay el Ser. Más allá de la guerra y de la paz está la mera errancia de la usura del ente en el autoaseguramiento del ordenar desde este vacío del estado del abandono del Ser. Guerra y paz, cambiadas en su in-esencia, están acogidas en la errancia $y$, al haberse hecho irreconocibles en vistas a una diferencia, han desaparecido en el mero desarrollo del hacer cada vez más cosas. La pregunta sobre cuándo va a haber paz no se puede contestar, no porque la duración de la guerra sea imprevisible sino porque la misma pregunta pregunta por algo que ya no existe, porque tampoco la guerra es ya nada que pudiera desembocar en una paz. La guerra se ha convertido en una variedad de la usura del ente, que se continúa en una paz" (M. Heidegger, Vorträge und Aufsätze, op. cit., p. 88; en español, p. 83).

${ }^{37} \mathrm{H}$. Blumenberg, La posibilidad de comprenderse, op. cit., p. 38.
} 
mente. La esencia del mal es entonces la ira de la sedición que nunca se desencadena plenamente, y que cuando lo hace se disimula de nuevo y en su amenazar se esconde cuando ya no lo está" ${ }^{38}$.

Esta esencia del mal que se despliega ahora como la ira de la sedición se puede considerar también como el incremento sutil del "éxodo epocal de todos los posibles nichos de recogimiento en la latencia" ${ }^{39}$. Este éxodo no es otra cosa que el despliegue del terror. En este contexto, podemos decir pues que lo que aquí hemos caracterizado, siguiendo a Heidegger, como la ira de la sedición es realmente el terror que ya se ha tomado nuestro mundo anunciando su fin con un gran estruendo. Pero esta invasión no es otra cosa más que la propia naturaleza histórica de Occidente, pues la ira es realmente la palabra fundacional de nuestra forma actual de civilización. Así pues, podemos afirmar entonces que el pensamiento apocalíptico de la historia del ser es también una meditación pensante sobre la temporeidad propia de la ira. Es decir, el cumplimiento del antiguo cielo y la antigua tierra implica el tiempo de la ira. Pero en medio de la desolación del fin del mundo se hace imprescindible cantar esta historia, como lo indica el propio Homero al comienzo de la Iliada:

"La ira canta, oh diosa, del Pelida Aquiles, maldita, que causó a los aqueos incontables dolores, precipitó al Hades muchas vidas de héroes y a ellos mismos los hizo presa para los perros y para todas las aves -y así se cumplía el plan de Zeus-, desde que por primera vez se separaron tras haber reñido el Atrida, soberano de hombres, y Aquiles, de la casta de Zeus"40.

\footnotetext{
${ }^{38}$ M. Heidegger, Feldweg-Gespräche, op. cit., pp. 207-208.

${ }^{39}$ P. Sloterdijk, Luftbeben. An den Quellen des Terrors, Frankfurt, Suhrkamp, 2002; Temblores de aire. En las fronteras del terror, Valencia, Pre-textos, 2003, p. 93.

${ }^{40}$ Homero, Iliada, Madrid, Gredos, 1993, 1, 1-7, p. 107. Sloterdijk muestra cómo Occidente se fue abriendo paso a partir de esta declaración heroica y glorificación de la ira: "El tono de los primeros versos propone el programa: las almas de los héroes vencidos -aquí llamados de manera formal, pero en general representados más bien como fantasmas en penumbra- se precipitan al Hades y de sus inanimados cuerpos Homero dice: «ellos mismos» son devorados a cielo abierto por aves y perros./ Con eufórica mesura se desliza la voz del cantor sobre el horizonte de aquella existencia de la que se pueden contar cosas. Ser griegos y oír esa voz significa, durante la época clásica una y la misma cosa. Allí donde se percibe, una cosa queda claro de inmediato: paz y guerra son dos denominaciones para sendas fases de un contexto vital en el que nunca se pone en cuestión el pleno empleo de la muerte. También el hecho de que el héroe encuentre prematuramente la muerte forma parte del mensaje de la epopeya. Si alguna vez tuvo sentido la palabra "glorificación de la violencia", ésta sería la de este introito al más antiguo documento de la cultura europea. Sin embargo, significaría casi lo contrario de aquello que se pretende en su uso actual, inevitablemente desaprobatorio. Cantar la ira significa hacerla memorable, pero lo que es memorable está siempre próximo a aquello que resulta impresionante y perpetuamente estimable. Estas valoraciones son tan opuestas a la manera de pensar y de sentir de los
} 
Como lo indica el poeta, el comienzo de nuestra historia está determinado por la ira. $\mathrm{Y}$ en el canto hacemos presente nuestro dolor y temor. El poder nombrar las cosas que en lo más profundo nos inquietan es, sin duda, el poder de cambiarlas y doblegarlas. Como sabemos, el nombrar es, para Blumenberg, la magia que inaugura un nuevo tiempo, pues esta onomathesia está permitida por Dios y nos acerca al mandato de la creación: "En vez de hágase, el menos imperioso llámese" ${ }^{41}$. ¿Podemos entonces cantar la historia de la ira sin quedar presos del pavor al nombrar el fin del mundo?

Si bien el tiempo de la ira se proyecta al hundimiento del antiguo cielo y la antigua tierra, aunque como dice el Apocalipsis de Juan el diablo "sabe que le queda poco tiempo" 42 , resulta claro también que este tiempo debería poder modificar el sentimiento del mundo para que pueda despertar el hombre dormido. Pero el tiempo de la ira es un tiempo limitado. En las palabras de Juan, nos topamos aquí con una fórmula que no se puede expresar en términos conceptuales. Estas palabras señalan, más bien, que "el resuelto poder de hacer el mal de los hombres está a su vez bajo la presión del tiempo"43.

Aunque la ira se proyecte temporalmente lleva consigo en su proyección su caducidad, pues tiene también el tiempo contado. Como lo anuncia el Evangelio de Mar$\cos$, el fin de este mundo está precedido por la destrucción, la desolación, la guerra y la muerte. Estos acontecimientos son necesarios en el plano temporal para que se dé la revelación del fin de los tiempos. En ellos se anuncia también la venida de lo salvador que inaugurará la nueva Jerusalén. En el Apocalipsis de Juan se señala esta buena nueva del modo siguiente:

\begin{abstract}
"Vi entonces un cielo nuevo y una tierra nueva, porque el primer cielo y la primera tierra habían desaparecido y el mar ya no existía. Y vi bajar del cielo, de junto a Dios, a la ciudad santa, la nueva Jerusalén, ataviada como una novia que se adorna para su esposo. Y oí una voz potente que decía desde el trono: Esta es la morada de Dios con los hombres; él habitará con ellos y ellos serán su pueblo" ${ }^{\prime 4}$.
\end{abstract}

Marcos señala igualmente que ante las noticias del estruendo del fin del mundo no hay que alarmarse. Así también Heidegger anota que en medio de la desolación provocada por la crudeza de la guerra no se debe perder la calma y hundirse en la

\footnotetext{
modernos que habrá que admitirlo: nos seguirá estando vedado un acceso auténtico al sentido propio de la comprensión homérica de la ira" (P. Sloterdijk, Zorn und Zeit. Politisch-psychologischer Versuch, Frankfurt, Suhrkamp, 2006; Ira y tiempo. Ensayo psicopolítico, Madrid, Ediciones Siruela, 2010, pp. 12-13).

${ }^{41}$ H. Blumenberg, La posibilidad de comprenderse, op. cit., p. 45.

${ }^{42}$ Ap. 12, 12.

${ }^{43} \mathrm{H}$. Blumenberg, La posibilidad de comprenderse, op. cit., p. 108.

${ }^{44}$ Ap. 21, 1-3.
} 
desesperanza nihilista. Si bien estos acontecimientos son profundamente desconcertantes para el pensamiento, hay que leer en ellos no sólo la crudeza de su tiempo caduco sino también la apertura de lo nuevo, de lo salvador. Reconocer esto salvador, sin subestimar empero el peligro del presente, es la perspectiva que quiere mostrarle Heidegger al joven en su diálogo acaecido en la oscuridad de la noche en un campo de concentración en Rusia.

Ahora bien, podemos asumir esta perspectiva como un acto de supervivencia en sentido blumenbergiano. En efecto, la meditación dialógica emprendida por Heidegger en este texto de 1946 busca abrir, tanto para el viejo como para el joven perturbado por los acontecimientos de la guerra y que quiere comprender las responsabilidades históricas de su presente, un camino de curación, que en medio de la distancia los pueda aproximar abriéndolos al pleno reconocimiento de lo que aquí sucedió. Este reconocimiento es la posibilidad para encontrar juntos una morada común. Como lo ha resaltado Blumenberg, frente a la crudeza de la desolación provocada por la guerra y en medio del duelo más profundo y errático, al observador de los campos de batalla no le queda otra alternativa que dar un salto para dominar en la distancia el absolutismo de la realidad que lo espanta. Gracias a este salto se puede vencer con un rodeo metaforológico todo lo desconcertante que perturba. Esta distancia así obtenida incluye a la vez "la capacidad de prevención, de adelantamiento a lo aún no ocurrido, el enfoque hacia lo que está ausente tras el horizonte" 45 .

En esta anticipación el observador de los acontecimientos de devastación provocados por la guerra puede llegar a dominar su temor. Si bien reconoce la contingencia de su tiempo, este observador anticipa la luz que vendrá en un momento futuro. Podemos entonces señalar ahora que el diálogo en medio de la noche se revela como un acto de delegación en sentido blumenbergiano. Así pues, en medio de la fractura de la existencia provocada por la desolación de la guerra el pensador quiere a continuación "traspasar el mando, y por la acción de delegar hacer, también en lo que toca a otros, como si fuera él mismo quien lo hace" ${ }^{" 46}$. Es decir, ante el incremento del desierto el testigo de semejante desolación quiere con su palabra meditativa delegar en los que vendrán la necesidad de responder ante la inquietud de su presente. Esta respuesta es igualmente un acto de protección de una historia común compartida que se proyecta hacia su propio fin. Con este gesto de "traspasar el mando" se quiere señalar también que el hombre debe asumir "-aunque sólo sea retóricamente- el papel de guardián de la caótica herencia: un pastor del ser" ${ }^{\text {47 }}$. Como podemos ver, se pro-

\footnotetext{
${ }^{45}$ H. Blumenberg, Arbeit am Mythos, Frankfurt, Suhrkamp, 1996, p. 11; Trabajo sobre el mito, Barcelona, Paidós, 2003, p. 12.

${ }^{46}$ H. Blumenberg, Begriffe in Geschichten, Frankfurt, Suhrkamp, 1998; Conceptos en historias, Madrid, Editorial Síntesis, 2003, p. 81.

${ }^{47}$ H. Blumenberg, La posibilidad de comprenderse, op. cit., p. 149.
} 
duce aquí una fusión metafórica de la palabra apocalíptica con el discurso pastoral que enuncia la historia del ser.

Pero no olvidemos que el acto de proteger está siempre en correlación directa con la posibilidad de la destrucción. Por esta razón, tanto para Blumenberg como para Heidegger, se hace necesario proteger la actividad llevada a cabo por la memoria en la vida humana. Sobre todo, si tenemos en cuenta que a menudo se busca dejar en el pasado todo aquello que ha acontecido sin traerlo de nuevo a la memoria. Así pues, cantar la historia de la ira, de aquello adherido desde un comienzo a nuestro decurso histórico y que en el hundimiento del antiguo cielo y la antigua tierra anuncia un nuevo cielo y una nueva tierra, permite vaticinar en un gesto de delegación proyectiva y rodeo metaforológico "la morada de Dios con los hombres" 48 .

Este gesto es realmente una intensificación de la anamnesis en sentido platónico. Si bien no es posible una respuesta desde el concepto al sentido del fin del mundo, es posible empero su respuesta en la cura, en la medida en que "una tal respuesta no se refiere a ninguno de los objetos que conocemos, ni a su totalidad en cuanto un mundo como aquel en que vivimos"49. Esta respuesta nos retrotrae, por tanto, a aquello que ha sido tapado en el grito de la ira y que demanda de nosotros nuevos oídos para escuchar lo que se anuncia en silencio, aquello que pide que sea de nuevo nombrado una vez más. Es decir, nos pide evocar de nuevo con la palabra el retorno de Mnemosyne. Se trata entonces de poder delegar en la palabra la retención de lo salvador en medio de la desolación. Tal vez, por esta razón, Heidegger en el semestre de verano de 1952 invitó, de una manera inusual en sus lecciones, a sus estudiantes a visitar el museo para ver la exposición Hablan los prisioneros de guerra ${ }^{50}$. Esta invitación buscaba que los jóvenes escucharan una voz insonora que habla desde la distancia. De esta manera, los exhortó también a no permitir que está voz desaparezca de su oído interior:

\footnotetext{
${ }^{48}$ Ap. 21-3.

${ }^{49} \mathrm{H}$. Blumenberg, La posibilidad de comprenderse, op. cit., p. 115.

${ }^{50} \mathrm{Si}$ bien todos sabemos la prevención justificada de Heidegger por el museo como garante de la memoria cultural de un pueblo, en la medida en que la cultura misma en su calidad de objeto de cuidado se ha convertido en el mundo moderno en "una política cultural" (M. Heidegger, Holzwege, op. cit., p. 70; en español, p. 64), debemos retomar ahora esta inusual invitación a sus jóvenes estudiantes como una apelación a un espacio de protección del pasado, libre de la instrumentalización política de la memoria. Con ello buscaba que lo protegido no se pierda en la administración burocrática del recuerdo. En la sociedad contemporánea, donde el propio mundo ha devenido museo, el estado administración del museo y los ciudadanos sus vigilantes, podemos reconocer "cómo se cumplen las funciones de la memoria y la amonestación: se pretende que determinadas instituciones, ruinas o construcciones no sean visitadas. De hecho, porque no hay prácticamente nada para lo que no se pudiera fundar una sociedad protectora. Nos ejercitamos protegiendo. Y esto a su vez es tan merecedor de protección que debería ser protegido de cualquier tipo de epílogo (Nachrede) que se le intente poner, en especial del difamatorio" (H. Blumenberg, La posibilidad de comprenderse, op. cit., pp. 148-149). Para Heidegger, el único lugar donde se puede proteger aquello digno de ser guardado en el recuerdo es justamente la palabra evocativa que se anuncia en la forma de pensamiento.
} 
"Pensar es recordar. Pero recordar es algo distinto de un fugaz hacer presente de nuevo lo pasado. El recuerdo piensa lo que nos afecta. Nosotros no estamos todavía en el espacio adecuado para reflexionar sobre la libertad, y ni siquiera para hablar de ella mientras cerremos también la mirada ante esta aniquilación de la libertad"51.

Como podemos ver, esta invitación a poner en la mira la aniquilación de la libertad lleva consigo un gesto político que busca quebrar el decurso de los acontecimientos históricos, delegando de una manera proyectiva la culminación de su iluminación definitiva. Como lo señala el evangelista, sólo al final del tiempo los hombres verán cara a cara a lo salvador y "llevarán su nombre en la frente" 52 . La anticipación de este cara a cara es tal vez lo que motiva a Heidegger al silencio ante el pavor de la guerra, pues en este silencio se evoca no un mero recoger lo que tenemos al frente, sino más bien "el mensaje de aquello a lo que estamos ofrecidos en cuanto existimos a la manera humana, un mensaje que supera todo hacer y omitir" 53 . Este mensaje es realmente la epifanía del silencio que abre un "nuevo cielo y una nueva tierra".

A lo largo del presente texto hemos querido mostrar que, si bien los acontecimientos históricos de nuestro siglo, la guerra generalizada, la devastación del mundo y la ausencia de una morada en común, nos ponen prima facie ante una realidad realmente desconcertante, también es cierto que en medio de estos acontecimientos se abre un nuevo espacio que debe ser escuchado. Poder hacerlo depende de la agudeza de nuestra mirada y que, como lo señala el texto bíblico, despierte el hombre dormido.

Siguiendo a Heidegger, señalamos que los acontecimientos históricos concretos, por ejemplo, la guerra, deben ser examinados en el horizonte amplio del acontecer destinal de la historia del hombre occidental, sin caer empero en una vana imputación rápida de responsabilidades históricas concretas. Esta mirada nos permite empero retrotraer los acontecimientos a su origen esencial y destinal. Así pues, la devastación del mundo acaecida en la guerra nos pone ante una realidad más esencial que la simple destrucción que vemos por doquier, a saber, la expulsión de Mnemosyne. De acuerdo con Hölderlin, podemos señalar entonces que esta expulsión acontece cuando el hombre se erige como símbolo de sí mismo, extraviándose en su errancia y perdiendo así su voz para llamar a lo salvador. Sin duda, este extravío es fuente de la proyección histórica del desenfreno humano y de su voluntad de aniquilación en aras de satisfacer las pretensiones cada vez más desmedidas del hombre. Sin embargo, no hay ahora algo que pueda contrarrestar este poder autorreferencial.

Tanto para Heidegger como para Blumenberg, la continua expulsión de Mnemosyne incrementa nuestro desconsuelo y, por esta razón, sólo podrá ser contrarrestada

\footnotetext{
${ }^{51}$ M. Heidegger, Was heisst denken?, op. cit., p. 159; en español, p. 214.

${ }_{52}^{52}$ Ap. 22, 4.

${ }^{53}$ M. Heidegger, Was heisst denken?, op. cit., p, 157; en español, p. 212.
} 
por medio de un retorno decidido de lo desterrado. Este retorno se abrirá en nuestro presente, cuando logremos cantar nuestra historia de la ira, tal como lo proclamaba antes Homero. Tomando como pauta hermenéutica la exploración metaforológica de los asuntos humanos realizada por Blumenberg, podemos ver en el diálogo de noche, elaborado por Heidegger entre un joven y un viejo profesor en un campo de concentración en Rusia, un cierto intento meditativo y dialógico de encarar en el presente los acontecimientos desoladores de la guerra. Obviamente, estos eventos se proyectan más allá de las circunstancias particulares de una guerra determinada.

Este intento se puede también asumir como un gesto de sobrevivencia, pues aquí se busca que los participantes en el diálogo, el encuentro de dos generaciones, reconozcan la verdadera dimensión histórica de su presente y correspondan así a esta inquietud con una clara decisión meditativa. Pero esta decisión pasa necesariamente por el gesto metaforológico y político de la delegación, en el que se proyecta lo aquí escuchado para que más tarde pueda ser acogido de nuevo por las generaciones futuras. Sólo de este modo se podrá abrir "un nuevo cielo y una nueva tierra". Así pues, en el gesto de la delegación podemos ver de manera plástica lo revelado en el tono apocalíptico de conversar en torno al fin de los tiempos. En este contexto, queremos anotar que ya en el pastoreo del ser, que caracteriza el modo como Heidegger se posiciona frente a su presente histórico, se da una articulación estructural entre lo apocalíptico y lo metaforológico. Esta articulación es, en efecto, la condición de posibilidad del retorno de Mnemosyne. 